$16^{\text {th }}$ International Conference on

AEROSPACE SCIENCES \& AVIATION TECHNOLOGY,

ASAT - 16 - May 26 - 28, 2015, E-Mail: asat@ mtc.edu.eg Military Technical College, Kobry Elkobbah, Cairo, Egypt

Tel : +(202) 24025292 - 24036138, Fax: +(202) 22621908

\title{
EFFECT OF COOLING SLOPE CASTING PARAMETERS ON THE THIXOTROPIC MICROSTRUCTURE OF A356 ALUMINUM ALLOY
}

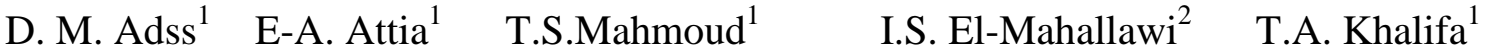 \\ ${ }^{I}$ Mechanical Engineering Department - Shoubra Faculty of Engineering - Benha University, Cairo, Egypt. \\ ${ }^{2}$ Mining, Petroleum and Metallurgical Department, Faculty of Engineering, Cairo University, Giza, Egypt.
}

\begin{abstract}
In the present paper, the effect of cooling slope casting (CSC) parameters process, typically, pouring temperature (T), cooling slope length (L) and tilt angle $(\theta)$, on the microstructure of A356 cast aluminum alloys was studied. The analysis of variance (ANOVA) statistical technique was carried out to clarify the relationship between the aforementioned parameters and the microstructure variables, typically, the shape factor (S.F.) and the grain size (G.S.) of the $\alpha$-Al primary phase. The uniformity of the microstructure in both the axial and radial positions of the ingots was also evaluated statistically. The results revealed that the tilt angle has the highest significant effect on both shape factor and grain size. The shape factor exhibited maximum value of about 0.812 for ingots poured at $\theta=30^{\circ}, \mathrm{L}=300 \mathrm{~mm}, \mathrm{~T}=630$ ${ }^{\circ} \mathrm{C}$. The minimum grain size was about $32.85 \mu \mathrm{m}$ for ingots casted at $\theta=60^{\circ}, \mathrm{L}=200 \mathrm{~mm}, \mathrm{~T}$ $=630{ }^{\circ} \mathrm{C}$. Ingots poured at $\theta=60^{\circ}, \mathrm{L}=300 \mathrm{~mm}, \mathrm{~T}=630{ }^{\circ} \mathrm{C}$ exhibited the highest grain size uniformity. While ingots casted at $\theta=30^{\circ}, \mathrm{L}=400 \mathrm{~mm}, \mathrm{~T}=620^{\circ} \mathrm{C}$, exhibited the highest shape factor uniformity.
\end{abstract}

KEYWORDS: Cooling Slope Casting, A356 aluminum alloy, Semi-solid Processing, Microstructure.

\section{INTRODUCTION}

Thixoforming is a semi-solid processing (SSP) technique that has the advantage of both die casting and forging processes [1-5]. It uses semi-solid slurries that has a thixotropic property, i.e. it can be flow like a liquid when sheared and when it at rest it solidifies again $[3,5]$. Such technique is used to produce parts needed for the automotive industry [2,3,6,7]. In thixoforming a specialized non-dendritic (thixotropic) feedstock is required. The nondendritic feedstock microstructure can be obtained by a variety of means during cooling including mechanical stirring and electromagnetic stirring [8-10]. Such techniques involve application of some sort of external shearing action. Recently, a simple and versatile technique known as cooling slope casting (CSC) was developed to produce thixotropic feedstock without the need of the application of external shearing action $[2-4,7,10,11]$. The semi-solid slurry is allowed to flow down an inclined surface. During this process, the shearing action takes place within the mush which slides down an inclined cooling slope due to natural gravity 
The influence of the CSC parameters on the microstructural characteristics of A356 aluminum ingots was studied by many investigators [1,2,4,7,11-13]. For example, Taghavi and Ghassemi [2] studied the effects of the cooling length and angle of inclined plate on the thixotropic microstructure of A356 aluminum alloy. The molten alloy with $680{ }^{\circ} \mathrm{C}$ superheat was poured on the surface of the inclined plate at different values of angles and lengths. It was found that the slope angle and cooling length of inclined plate affect the size and morphology of $\alpha$-Al grain. Hosseini et al.[1] investigated the effect of pouring temperature, cooling length and tilt angle of copper made plate on the microstructure of the A356 aluminum alloy. The molten alloy with the temperature of 680,650 and $625^{\circ} \mathrm{C}$ was poured on the surface of the plate where cooled with water circulation in various tilt angles $\left(30^{\circ}, 40^{\circ}, 50^{\circ}, 60^{\circ}\right)$ and lengths $(300,400,500,600,700 \mathrm{~mm})$. It was found that there is an optimum length in which minimum grain size and maximum sphericity can be obtained, at a constant tilt angle and pouring temperature. Also, it was found that there was a suitable tilt angle in which minimum grain size and maximum sphericity can be obtained, at a constant pouring temperature and length. There results indicate that condition of $60^{\circ}$ and $600 \mathrm{~mm}$ is suitable cooling plate tilt angle and pouring length presenting the minimum grain size of $81 \mu \mathrm{m}$ and maximum shape factor of 0.72 with highest uniformity. Haga et al. [12] studied the effects of the casting factors such as tilt angle and cooling length on the process to make semisolid slurry. The results show that these factors affect the behavior of the semisolid slurry on the cooling slope. The tilt of the slope is the factor that has major influence on the behavior of the semisolid slurry.

In the present study, the influences of the CSC parameters such as pouring temperature, cooling slope length and tilt angle of the inclined plate on the microstructure of A356 cast Al-Si aluminum alloy were investigated. The effect of the aforementioned parameters on the uniformity of the microstructure thought out the A356 aluminum ingots was also examined .The analysis of the experimental results was carried out using analysis of variance(ANOVA). The ANOVA is useful in understanding the effect of CSC parameters and their interactions on the microstructural characteristics of the $\alpha$-Al primary phase such as the shape factor (S.F.) and grain size (G.S.).

\section{EXPERIMENTAL PROCEDURES}

\subsection{Material}

In the present work, the A356 Al-Si cast aluminum alloy is used with the chemical composition shown in Table 1. The differential scanning calorimetric (DSC) analysis showed that the liquidus and solidus temperatures of the alloy are 615 and $572{ }^{\circ} \mathrm{C}$, respectively.

Table 1 Chemical composition of A356 aluminum alloys (wt.-\%).

\begin{tabular}{cccccccc}
\hline Alloy & $\mathrm{Si}$ & $\mathrm{Mg}$ & $\mathrm{Fe}$ & $\mathrm{Cu}$ & $\mathrm{Mn}$ & $\mathrm{Ti}$ & $\mathrm{Al}$ \\
\hline $\mathrm{A} 356$ & 7.38 & 0.279 & 0.149 & 0.002 & 0.003 & 0.141 & $\mathrm{Bal}$. \\
\hline
\end{tabular}

\subsection{Cooling Slop Casting Process}

The CSC process was carried as follows: about $850 \mathrm{~g}$ of A356 alloy was melted at 680 ${ }^{\circ} \mathrm{C}$ in a graphite crucible located at a resistance furnace. After complete melting, degassing process by dry argon inert gas was carried out to remove any undesirable dissolved gases in order to prevent the formation of gas bubbles inside the ingots, then the molten alloy was allowed to cool down to the required pouring temperature, then poured on the surface of an inclined $100 \mathrm{~mm}$ wide mild steel plate as shown in Fig. 1. The plate is coated with a thin layer of hard Chromium to prevent adhesion between the molten metal and the plate. The cooling plate tilt angle was adjusted to desired angles of with respect to the horizontal plane. Also, the 
flow length of the molten metal over the plate can be adjusted to the required pouring length. The semisolid metal formed at the end of the inclined plate collected in a steel mold located under the inclined plate then leaved to cool down. The steel mold had a diameter of $50 \mathrm{~mm}$ and height of $160 \mathrm{~mm}$ with a draft angle of $2^{\circ}$ for easy removal of the solidified ingot.

\subsection{Microstructural Investigations}

After solidification, the produced ingots were sectioned horizontally into discs, having $25 \mathrm{~mm}$ radius and5 $\mathrm{mm}$ thick, from the top, middle, and bottom sections as shown in Fig. 2. Metallographic specimens were ground and polished using standard metallographic techniques. The samples was etched using keller's etchant $(2 \mathrm{ml}$ Hydrofluoric acid, $3 \mathrm{ml}$ Hydrochloric acid, $5 \mathrm{ml} \mathrm{Nitric} \mathrm{acid,} \mathrm{and} 190 \mathrm{ml}$ distilled water), then examined using Olympus optical microscope. The metallographic images were taken from the wall zone (radius), mid-radius and center zone of the specimens as shown in Fig. 2. The size and shape factor of $\alpha$-Al grains were determined using image analyzing techniques. The shape factor of the grains was determined from the following equation [1]:

$$
\text { S.F. }=4 \pi A P^{-2}
$$

Where: $P$ is the perimeter and $A$ is the area of $\alpha-\mathrm{Al}$ grain. For a perfect circle, the shape factor would be one.

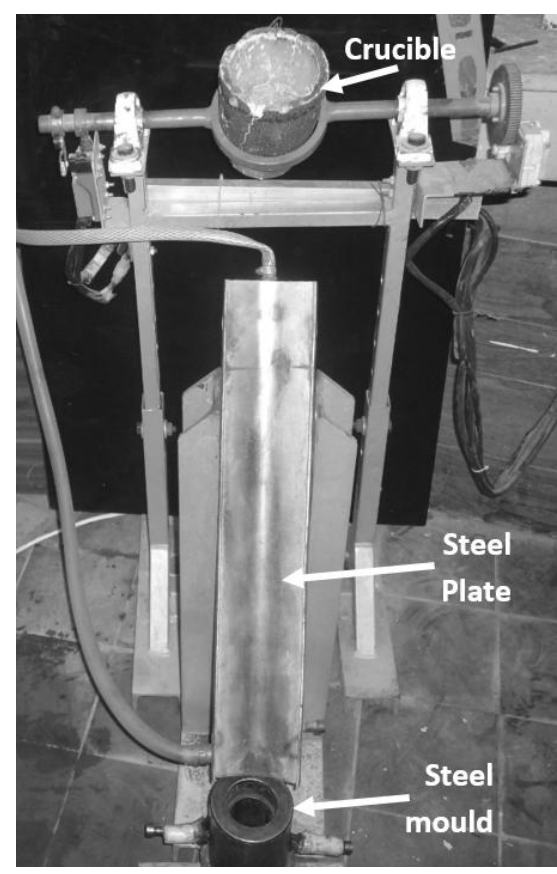

(a)

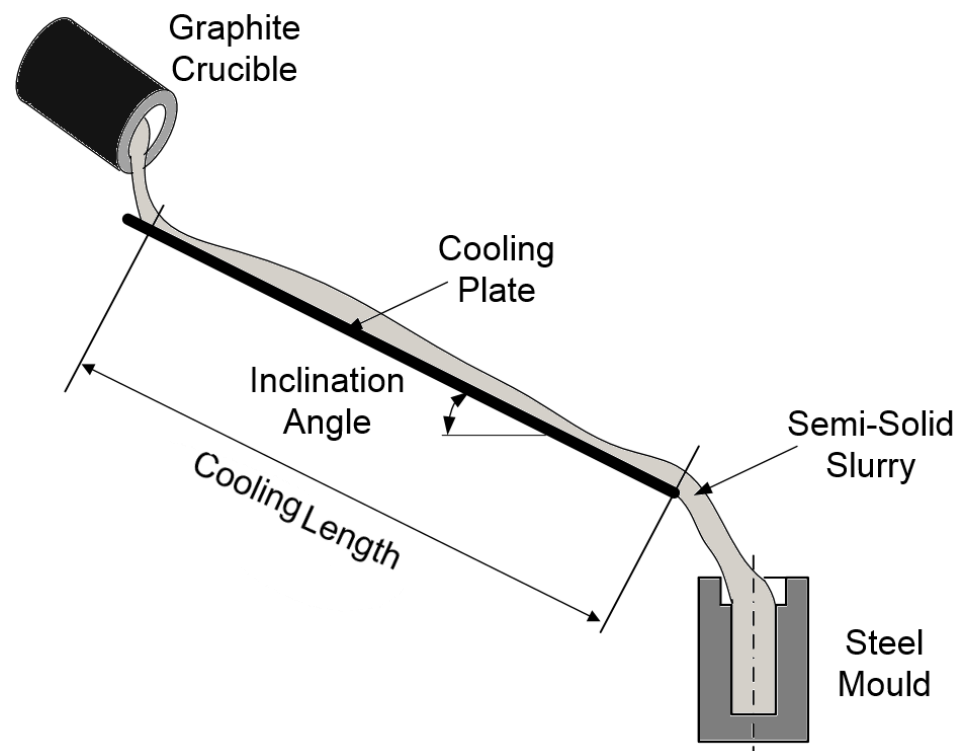

(b)

Fig. 1. The cooling slope casting (CSC) apparatus (a) a photograph (b) a schematic illustration 


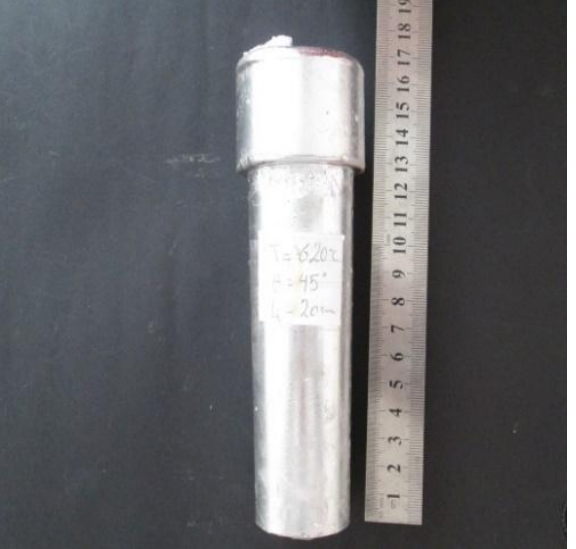

(a)
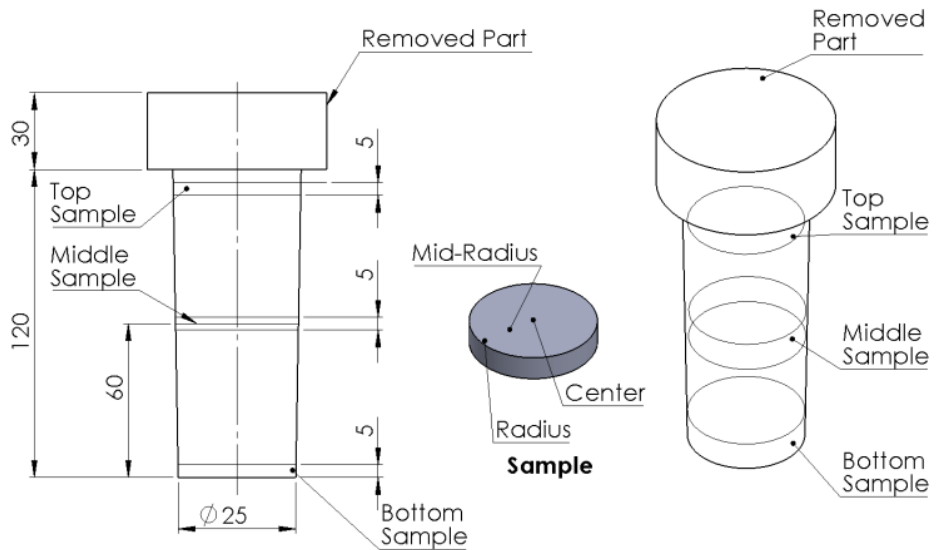

(b)

Fig. 2. (a) A photograph shows a typical A356 ingot and (b) a schematic illustration of the ingot showing the locations of the metallographic samples (Dimensions in $\mathrm{mm}$ )

\subsection{Design of Experiment (DOE)}

In order to investigate the effect of CSC process parameters on the different responses (i.e. grain size and shape factor), the three levels factorial design of experiment (DOE) technique was performed. The factorial design technique was adopted in order to investigate the different interactions between CSC variables. With factorial design one can have responses at all combinations of the factors levels. Other reason is the number of generated runs with three factors and three levels is acceptable from the economical perspective. The independent parameters are pouring temperature, tile angle and the cooling slope length. Table 2 summarizes the independent parameters and their levels. The pouring temperature levels were adopted based of the work of Ghavamodini et al. [4]. Also, the levels of the tilt angle were selected relying on the work of Haga et al. [13]. In addition the levels of the cooling slope length were selected as presented in the work of Hosseini et al. [1]. This design of experiment gives a total of 27 ingots.

The analysis of experimental results was carried out using analysis of variance (ANOVA) approach. The ANOVA is a very useful statistical method in understanding the effect of casting parameters and their interactions on the value of shape factor and grain size of $\alpha$-Al grains. From results of ANOVA one can obtain the most and lowest significant parameters. Furthermore, the relative standard deviation (RSD) has be used to determine the maximum uniformity of shape factor and grain size in both axial and radial directions of the ingot. The RSD gives the variation as a percentage of the mean (average). More uniform data yield a smaller RSD. It is expressed a relative relation between variation and data mean. It can be obtained according to the relation: $\operatorname{RSD}=\sigma / \mu$, where $\sigma$ : is the standard deviation and $\mu$ is the mean value of the data. The statiscial and ANOVA calculations were performed using MiniTab commercial statistical software.

Table 2. The independent parameters and their levels.

\begin{tabular}{|l|c|c|c|}
\hline \multirow{2}{*}{\multicolumn{1}{|c|}{ Parameters }} & \multicolumn{3}{|c|}{ Levels } \\
\cline { 2 - 4 } & $\begin{array}{c}\text { Level-1 } \\
(\text { minimum })\end{array}$ & $\begin{array}{c}\text { Level-2 } \\
(\text { mean })\end{array}$ & $\begin{array}{c}\text { Level-3 } \\
(\text { maximum })\end{array}$ \\
\hline Pouring Temperature $\left({ }^{\circ} \mathrm{C}\right)$ & 620 & 630 & 640 \\
\hline Cooling Plate Tilt Angle (Degree) & 30 & 45 & 60 \\
\hline Cooling Length $(\mathrm{mm})$ & 200 & 300 & 400 \\
\hline
\end{tabular}




\section{RESULTS \& DISCUSSION}

\subsection{Effect of CSC Parameters on the Grain Size of the primary $\alpha$-Al Phase}

Figures 3 and 4 shows typical micrographs of the microstructure of the A356 ingots poured at various CSC parameters. The micrographs were taken from different locations of the A356 ingots. It can be observed that the degeneration of the dendritic structure and refinement in the morphology of the primary $\alpha$-Al phase in the CSC ingots is the consequence of the fractional solidification that occurs on the cooling slope plate. Generally, the radius zones exhibited finer primary $\alpha$-Al grains than the mid-radius and center zones. This is due to the larger amount of heat dissipated from the molten metal through the wall of the mold allowing the formation of finer grains.

Figures 5 shows the variation of the average grain size of the primary $\alpha$-Al grains of the A356 ingots with the tilt angle at different pouring temperatures and cooling slope lengths, respectively. It has been found that, at constant pouring temperature and length, increasing the tilt angle from $30^{\circ}$ to $45^{\circ}$ decreases the average size of the primary $\alpha$-Al grains. For example, at constant pouring temperature of $620^{\circ} \mathrm{C}$ and cooling slope length of $200 \mathrm{~mm}$, increasing the tilt angle from $30^{\circ}$ to $45^{\circ}$ reduced the average size of the primary $\alpha$-Al grains from 59.82 to $54.22 \mu \mathrm{m}$. Increasing the tilt angle more than $45^{\circ}$ (i.e. to $60^{\circ}$ ) tends to increases the average size of the primary $\alpha$-Al grains. The increase of the tilt angle results in the increase of the shear stress that helps to break the dendritic microstructure and converts it to nearly more fine grains [1]. This result is obviously seen with the comparison of the microstructure at both tilt angle values of $30^{\circ}$ and $45^{\circ}$. When the tilt angle increased than a certain value this make the slurry passing the inclined plate with very high speed, decreasing the amount of heat dissipated from the molten metal that makes it reaches at the end of the inclined plate and collected in the die in the form of semi-solid with low solid particle content and high liquid fraction [15].

It has been found that, for ingots poured at $620^{\circ} \mathrm{C}$, increasing the cooling slope length reduces the average size of the primary $\alpha$-Al grains (see Fig. 5a). For example, at constant tilt angle of $30^{\circ}$, increasing the cooling slope length from 200 to $400 \mathrm{~mm}$ reduces the average grain of the primary $\alpha-\mathrm{Al}$ grains from 59.82 to $36.79 \mu \mathrm{m}$. At pouring temperatures higher than $620{ }^{\circ} \mathrm{C}$ (i.e. at 630 and $640{ }^{\circ} \mathrm{C}$ ), the effect of the cooling slope length could not clearly determined since the ingots showed practically the same average $\alpha$-Al grain size. The results revealed also that increasing the pouring temperature increases the average grain of the primary $\alpha-\mathrm{Al}$ grains. For example, at constant tilt angle of $30^{\circ}$ and cooling slope length of 200 $\mathrm{mm}$, increasing the pouring temperature from $620{ }^{\circ} \mathrm{C}$ to $630{ }^{\circ} \mathrm{C}$ reduced the average grain of the primary $\alpha$-Al grains from 59.82 to $43.73 \mu \mathrm{m}$. It has been reported [16] that high pouring temperature leads to decrease in nucleation, remelting the primary crystals and undesired grain growth. 


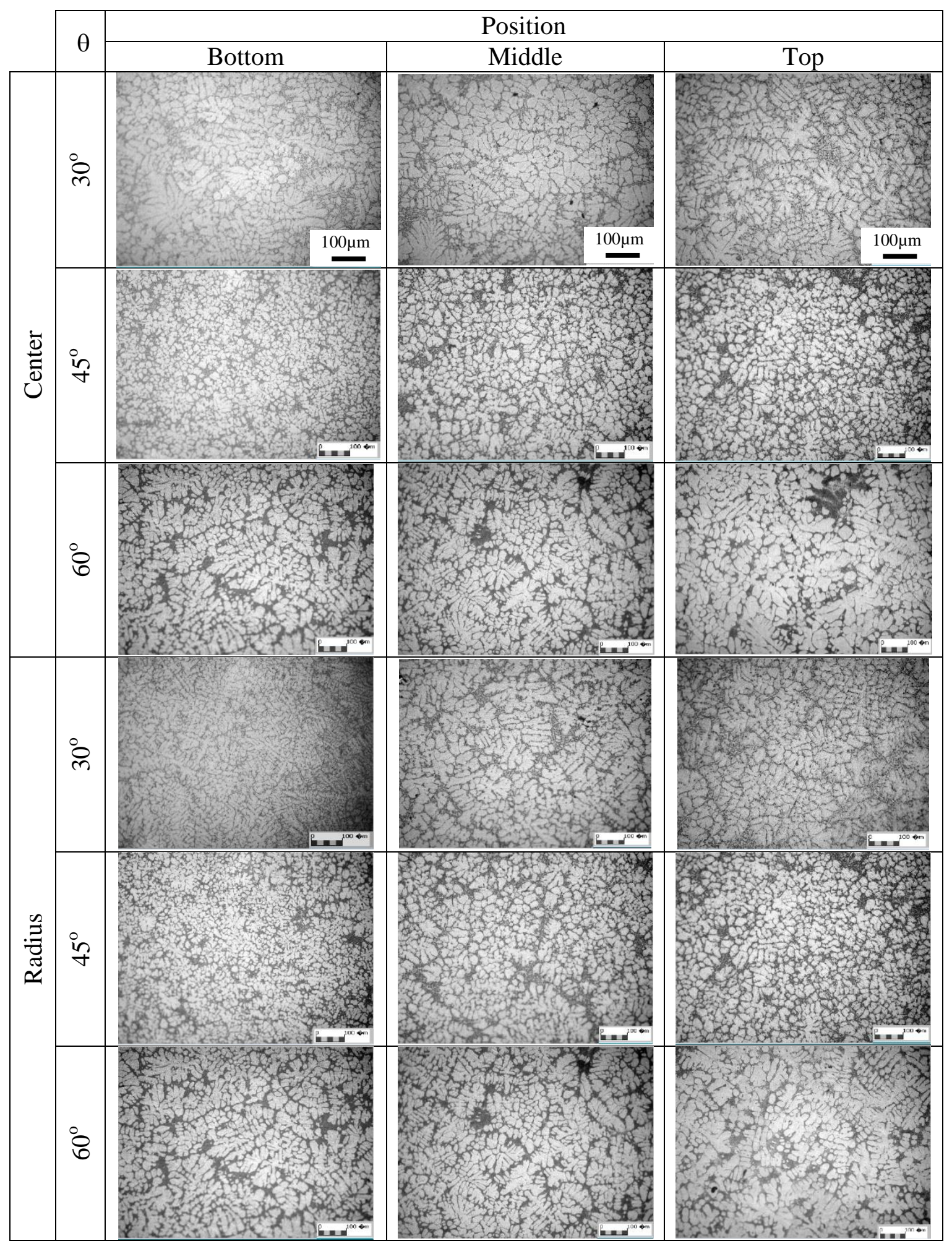

Fig. 3. Optical micrographs of the microstructure of the A356 alloy poured using several tilt angles $(\theta)$. The pouring temperature and cooling length were kept constant at $640{ }^{\circ} \mathrm{C}$ and 400 $\mathrm{mm}$, respectively. 


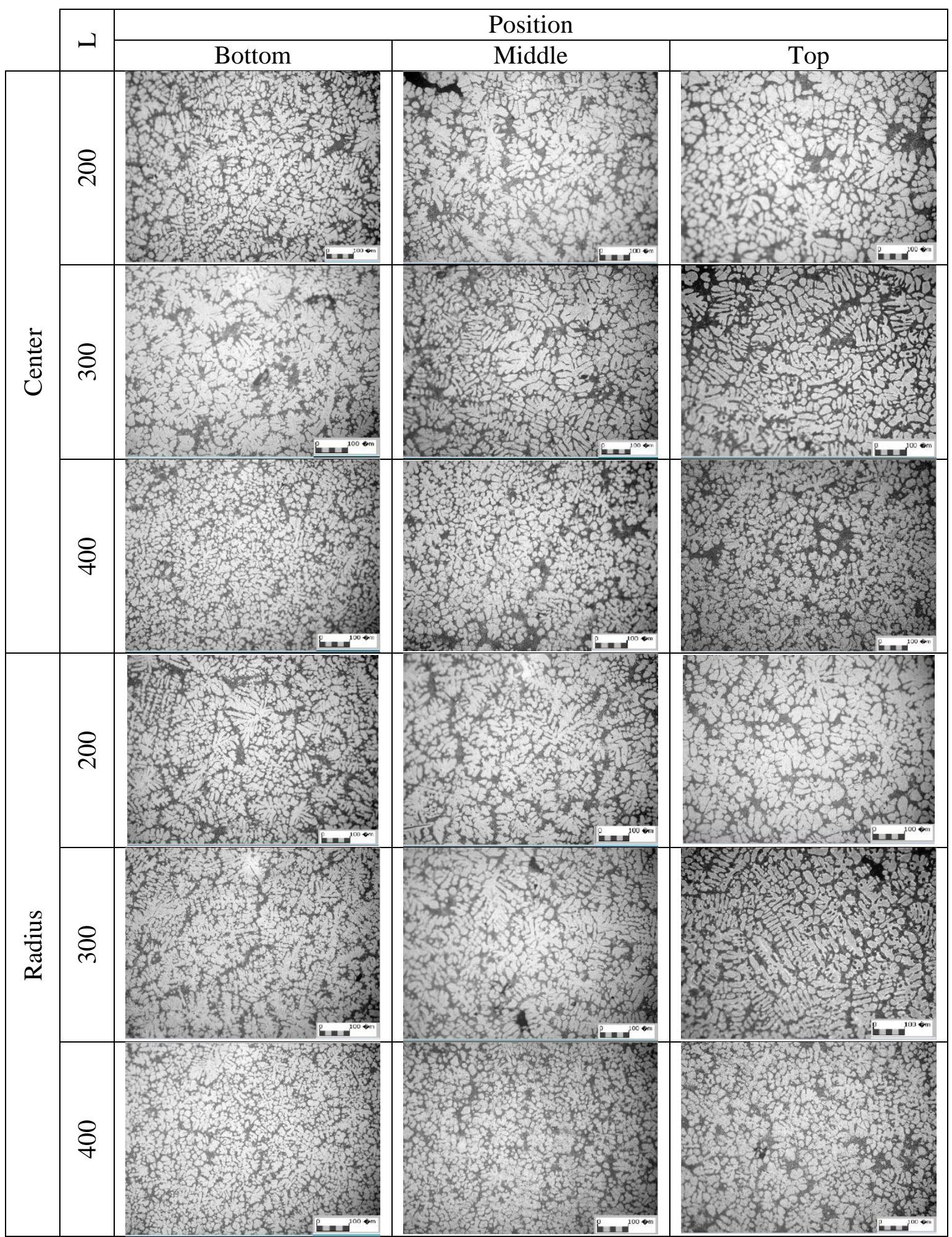

Fig. 4. Optical micrographs of the microstructure of the A356 alloy poured using several cooling slope lengths $(\mathrm{L})$. The pouring temperature and tilt angle were kept constant at $620{ }^{\circ} \mathrm{C}$ and $45^{\circ}$, respectively.

Figure 6 shows the variation of the primary $\alpha$-Al grains at both axial and radial directions with the cooling slope casting parameters studied in the present investigation. The bottom of the ingots exhibited the smallest grain size when compared with the top and middle positions. Also, the grains at the radius positions showed the smallest size when compared with the center and mid-radius positions. Increasing the cooling slope length reduces the size of the primary $\alpha-\mathrm{Al}$ grains at both the axial and radial positions of the ingots (see Fig. $6 \mathrm{c}$ and 
6d). At both axial and radial positions, increasing the tilt angle from 30 to $45^{\circ}$ reduces the size of the primary $\alpha$-Al grains. However, increasing the tilt angle from 45 to $60^{\circ}$ tends to increase the size of the primary $\alpha-\mathrm{Al}$ grains at both axial and radial positions (see Fig. 6a and $6 \mathrm{~b}$ ). The results showed also that, at both the positions increasing the pouring temperature from 620 to $630{ }^{\circ} \mathrm{C}$ reduces the size of $\alpha$-Al grains at the bottom, middle and top of the A356 alloy ingots. Increasing the pouring temperature above $630{ }^{\circ} \mathrm{C}$ (i.e. to $640{ }^{\circ} \mathrm{C}$ ) increases the grain size of the primary $\alpha-\mathrm{Al}$ grains. Such observation was noticed at the radial positions. In the radial position, the radius position (near wall position) exhibited largest grain size when compared with the mid-radius and center positions of the ingot.

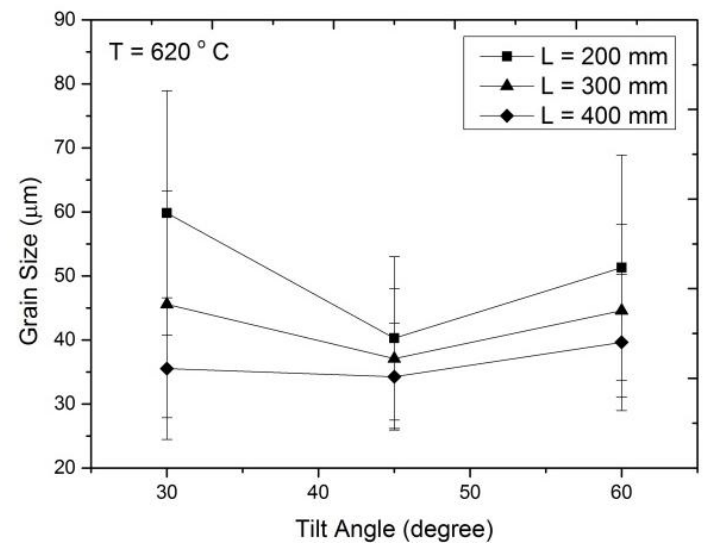

(a)

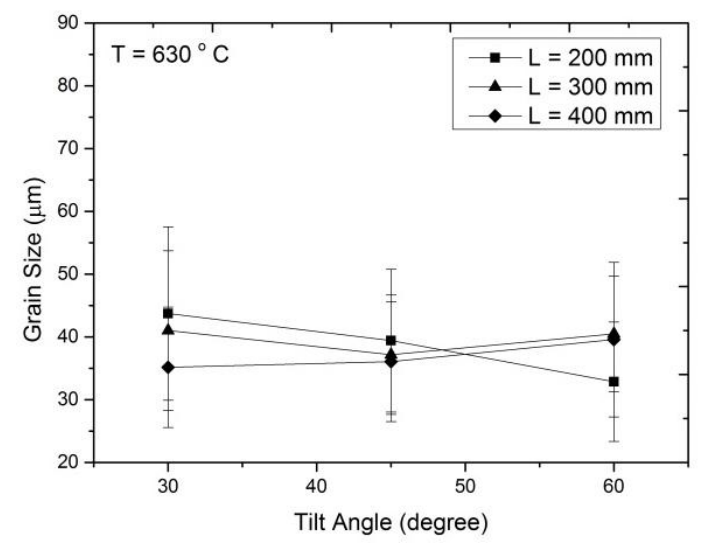

(b)

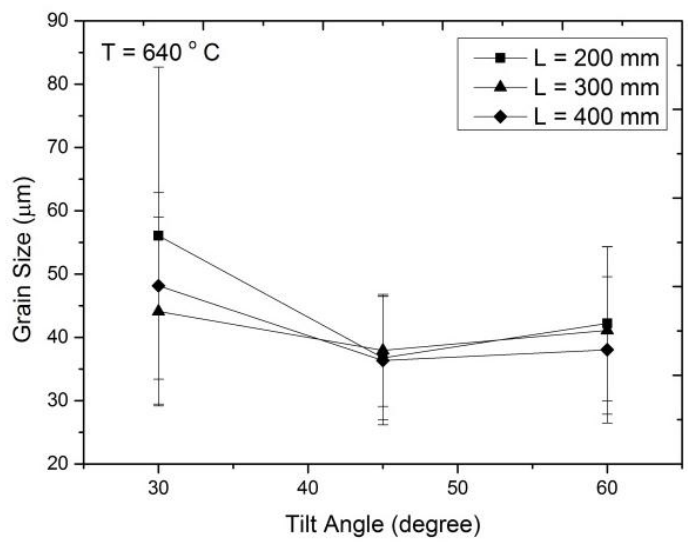

(c)

Fig. 5.Variation of the average grain size of the $\alpha$-Al primary grains with the tilt angle at different cooling lengths and pouring temperatures.

Figure 7 shows typical histograms of the size of the $\alpha$-Al primary grains at the top, middle and bottom positions of A356 ingot poured at at $45^{\circ}, 400 \mathrm{~mm}$ and $640{ }^{\circ} \mathrm{C}$. The values resulted from the RSD calculations of the size of the primary $\alpha$-Al grains revealed that the minimum value (i.e. maximum uniform grain size distribution) of about 0.14613 was obtained for ingots poured at $\theta=60^{\circ}, \mathrm{L}=400 \mathrm{~mm}$, and $\mathrm{T}=640^{\circ} \mathrm{C}$. The ingots poured at $\theta=30^{\circ}, \mathrm{L}=$ $200 \mathrm{~mm}$, and $\mathrm{T}=640{ }^{\circ} \mathrm{C}$ exhibited the maximum RSD value of about 0.557152 (i.e. the minimum uniform grain size distribution). Table 3 lists the ANOVA results for the size of the $\alpha-\mathrm{Al}$ primary grains. The analysis was carried out for a level of significance of 5 percent (i.e. the confidence limit is equal to 95 per cent). The last column in Table 3 shows the percentage of contribution $\left(\mathrm{P}_{\mathrm{c}}\right)$ of each factor on the total variation indicating the influence of the factors on the results. It can be observed that tilt angle $\left(\mathrm{P}_{\mathrm{c}}=28.97 \%\right)$, cooling slope length $\left(\mathrm{P}_{\mathrm{c}}=\right.$ $17.1326 \%)$, pouring temperature $\left(\mathrm{P}_{\mathrm{c}}=11.568 \%\right)$, the interaction tilt angle/cooling slope length $\left(\mathrm{P}_{\mathrm{c}}=11.5426 \%\right)$, and the interaction cooling slope length/pouring temperature $\left(\mathrm{P}_{\mathrm{c}}=13.56 \%\right)$ have the greatest statistical and physical significance on the grain size of $\alpha$-Al grains. It was also found that the interaction tilt angle/pouring temperature $\left(\mathrm{P}_{\mathrm{c}}=9.7268 \%\right)$ and the 
interaction tilt angle/cooling slope length/ pouring temperature $\left(\mathrm{P}_{\mathrm{c}}=7.5 \%\right)$ have lower significant effect on the grain size of the $\alpha$-Al primary grains. The results indicated that the tilt angle parameter has the highest statistical physical significance on the grain size of the $\alpha-\mathrm{Al}$ primary grains.

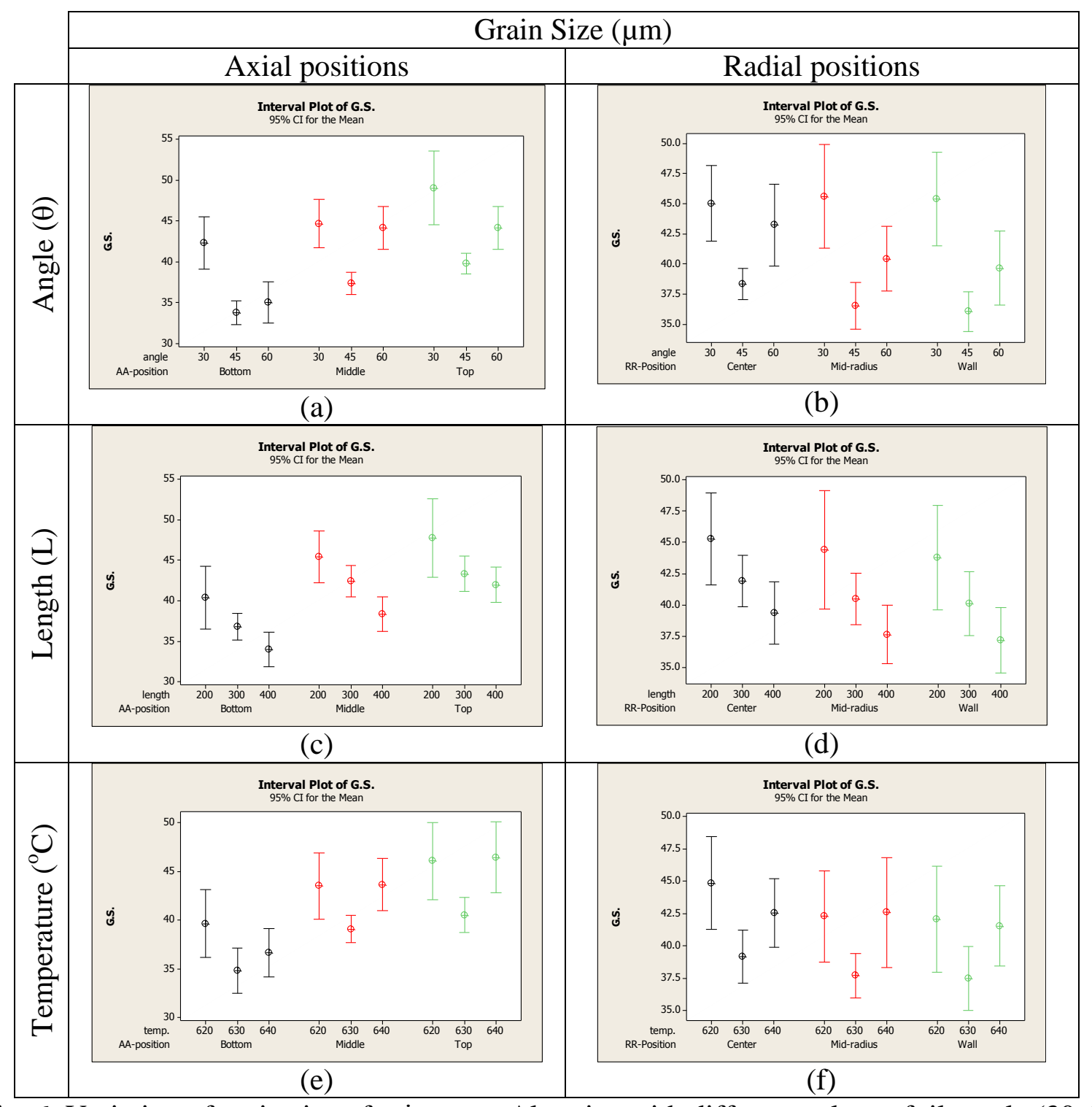

Fig. 6. Variation of grain size of primary $\alpha$-Al grains with different values of tilt angle $(30,45$ and $\left.60^{\circ}\right)$, cooling slope length $(200,300$ and $400 \mathrm{~mm})$ and pouring temperature $(620,630$ and $\left.640{ }^{\circ} \mathrm{C}\right)$ at both $(\mathrm{a}, \mathrm{c}, \mathrm{e})$ axial and $(\mathrm{b}, \mathrm{d}, \mathrm{f})$ radial positions.

Table 3. ANOVA table for the size of the $\alpha$-Al primary grains.

\begin{tabular}{|c|c|c|c|c|c|c|}
\hline $\begin{array}{c}\text { Source of } \\
\text { variation }\end{array}$ & DF & SS & MS & F & P & $\mathrm{P}_{\mathrm{c}}$ \\
\hline$\theta$ & 2 & 2853.30 & 1426.65 & 47.32 & 0.000 & 28.97 \\
\hline $\mathrm{L}$ & 2 & 1687.42 & 843.71 & 27.99 & 0.000 & 17.1326 \\
\hline $\mathrm{T}$ & 2 & 1139.38 & 569.69 & 18.90 & 0.000 & 11.568 \\
\hline$\theta \times \mathrm{L}$ & 4 & 1136.67 & 284.17 & 9.43 & 0.000 & 11.5426 \\
\hline$\theta \times \mathrm{T}$ & 4 & 958.01 & 239.50 & 7.94 & 0.000 & 9.7268 \\
\hline $\mathrm{L} \times \mathrm{T}$ & 4 & 1335.53 & 333.88 & 11.07 & 0.000 & 13.56 \\
\hline$\theta \times \mathrm{L} \times \mathrm{T}$ & 8 & 738.86 & 92.36 & 3.06 & 0.003 & 7.5 \\
\hline Residual & 216 & 6511.92 & 30.15 & & & \\
\hline Total & 242 & 9849.18 & & & & 100 \\
\hline \multicolumn{6}{|c|}{$\mathrm{S}=5.49070$ R-Sq. $=60.20 \%$ R-Sq. (adj) $=55.41 \%}$. \\
\hline
\end{tabular}

DF, degrees of freedom; SS, sum of squares; MS, mean square; F, F-test; $\mathrm{P}$, Statistical significance, $\mathrm{P}_{\mathrm{c}}$, percentage of contribution. 


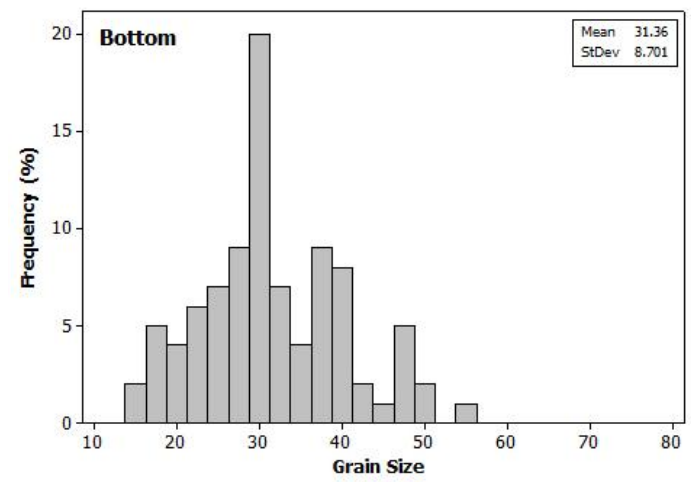

(a)

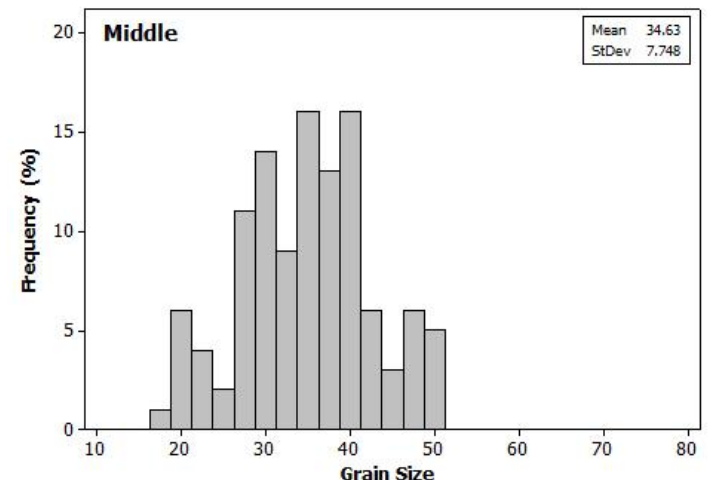

(b)

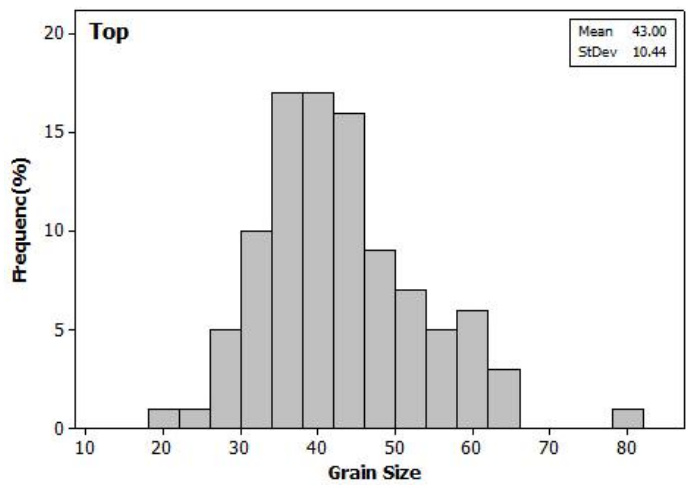

(c)

Fig. 7. A sample of the frequency plot (histogram) of the size of the $\alpha$-Al primary grains at the top, center and bottom positions of A356 ingot poured at $45^{\circ}, 400 \mathrm{~mm}$ and $640{ }^{\circ} \mathrm{C}$.

\subsection{Effect of CSC Parameters on the Shape Factor of the primary $\alpha$-Al Phase}

Figure 8 shows the variation of the average shape factor of the A356 alloy ingots with the tilt angle at different pouring temperatures and cooling slope lengths. At constant pouring temperature and cooling slope length, increasing the tilt angle reduces the average shape factor of the A356 alloy ingot. For example, at constant pouring temperature of $620{ }^{\circ} \mathrm{C}$ and pouring length of $200 \mathrm{~mm}$, increasing the tilt angle from 30 to $60^{\circ}$ reduces the average shape factor of the primary $\alpha$-Al grains from 0.7791 to 0.7384 In contrast, increasing the cooling slope length increasing the average shape factor of the ingots. For example, at constant tilt angle of $30^{\circ}$ and pouring temperature of $630^{\circ} \mathrm{C}$, increasing the cooling slope length from 200 to $400 \mathrm{~mm}$ increases the average shape factor of the primary $\alpha$-Al grains from 0.7891 to $0.7933 \mu \mathrm{m}$. Moreover, at constant tilt angle and cooling slope length, increasing the pouring temperature increases slightly the average shape factor of the primary $\alpha$-Al grains. For example, at constant tilt angle of $30^{\circ}$ and cooling slope length of $200 \mathrm{~mm}$, increasing the pouring temperature from $620{ }^{\circ} \mathrm{C}$ to $630{ }^{\circ} \mathrm{C}$ increases the average shape factor from 0.7791 to 0.7891

Figure 9 shows the variations of the average shape factor with the different cooling slope casting parameters at both axial and radius positions of the A356 alloy ingots. Generally, increasing the tilt angle reduces the shape factor at both axial (top, middle and bottom) and radial (radius, mid-radius and center) positions of the poured ingots. In contrast, increasing the pouring temperature increases the shape factor at both the axial and radial positions of the A356 ingots (see Fig. 9c and 9d). The top positions of the ingots exhibited higher shape factor than the bottom and middle of the ingots. Moreover, the radius (near wall) positions exhibited higher shape factor than the center and mid-radius positions of the ingots. Increasing the pouring temperature from 620 to $630{ }^{\circ} \mathrm{C}$ increases slightly the shape factor of the $\alpha$-Al primary grains. Such observation was noticed at both axial and radial positions of the 
ingots. Further increase in the pouring temperature (i.e. to $640{ }^{\circ} \mathrm{C}$ ) tends to reduce the shape factor of the $\alpha-\mathrm{Al}$ primary grains at both axial and radial positions of the ingots.

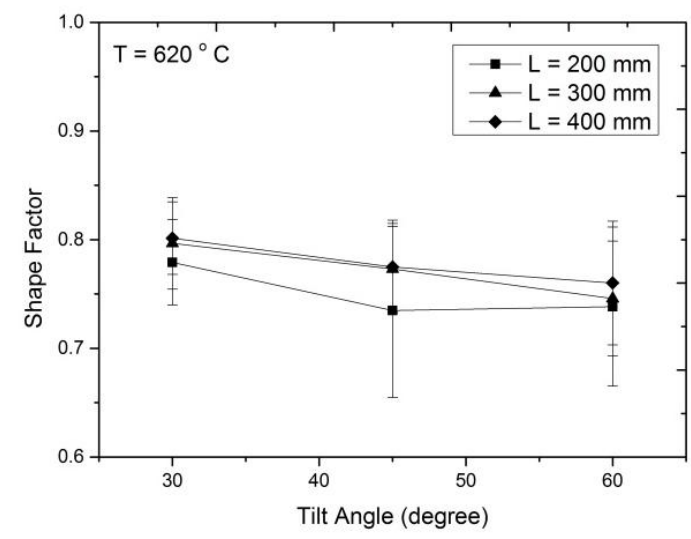

(a)

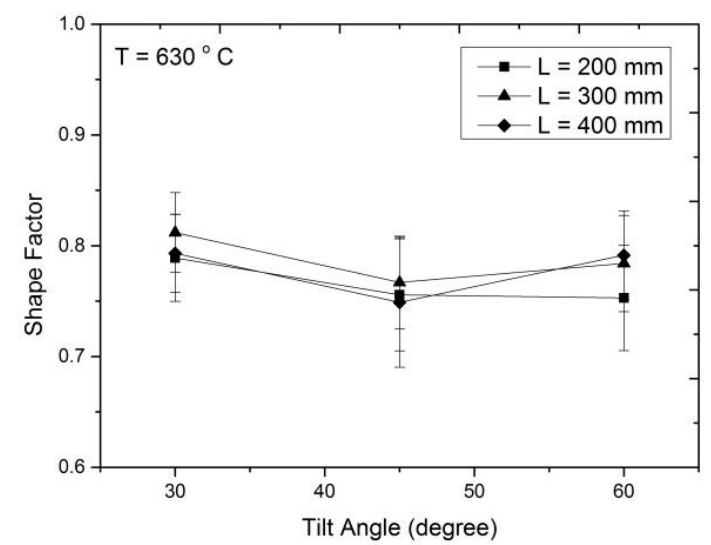

(b)

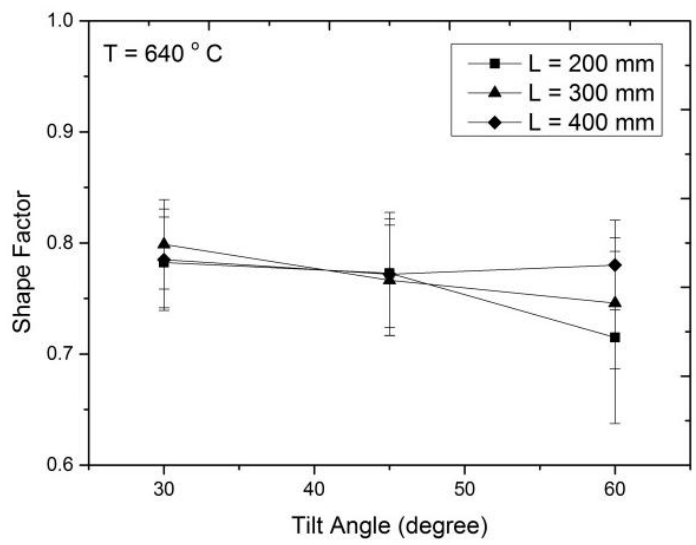

(c)

Fig. 8. Variation of the average shape factor of the $\alpha$-Al primary grains with the tilt angle at different cooling lengths and pouring temperatures.

Figure 10 shows typical histograms the shape factor distribution of the $\alpha$-Al primary grains at the top, middle and bottom positions of ingot poured at $30^{\circ}, 200 \mathrm{~mm}$ and $620{ }^{\circ} \mathrm{C}$. The minimum RSD value of the shape factor was about 0.026955 for ingots poured at $\theta=30^{\circ}$, $\mathrm{L}=300 \mathrm{~mm}$ and $\mathrm{T}=640{ }^{\circ} \mathrm{C}$. While the maximum $\mathrm{RSD}$ value was about 0.20424 for ingots poured at $\theta=45, \mathrm{~L}=200 \mathrm{~mm}$ and $\mathrm{T}=620{ }^{\circ} \mathrm{C}$. Table 4 shows the results of the ANOVA for the porosity content. The analysis was carried out for a level of significance of 5 per cent. From the analysis of Table 4 , it can be observed that tilt angle $\left(\mathrm{P}_{\mathrm{c}}=43.885 \%\right)$ and cooling length $\left(\mathrm{P}_{\mathrm{c}}=15.537 \%\right)$ have the highest statistical and physical significance on the shape factor of the $\alpha$-Al primary grains. The pouring temperature $\left(\mathrm{P}_{\mathrm{c}}=3.044 \%\right)$ have lowest statistical and physical significance on the shape factor.

From the aforementioned results, it can be concluded that the tilt angle has the most significant effect on both the grain size and shape factor of the $\alpha$-Al primary grains. While the pouring temperature has the lowest significant effect on both the grain size and shape factor of the $\alpha$-Al primary grains. Such results were reported by many workers $[1,13,15,16]$. Pouring the molten metal on a slope plate with large angle make the metal flow rapidly and this leads to poor formation in solid fraction due to low heat transfer from the molten metal that results in coarse grains with bad shape factor, so when pouring the molten metal on a cooling slope plate with small tilt angle this give the chance of increasing the number of nucleated and detached crystals that produces fine grains with better shape factor, but if the tilt angle become very small this leads to more time needed for the metal to pass on the slope plate and as a result the cooling rate will be very large which leads to the sticking of the semi-solid metal on the cooling plate and the die will not be completely filled with the metal. In the 
present investigation, it has been found that a tilt angle of $45^{\circ}$ is the most suitable angle for pouring the A356 alloy.

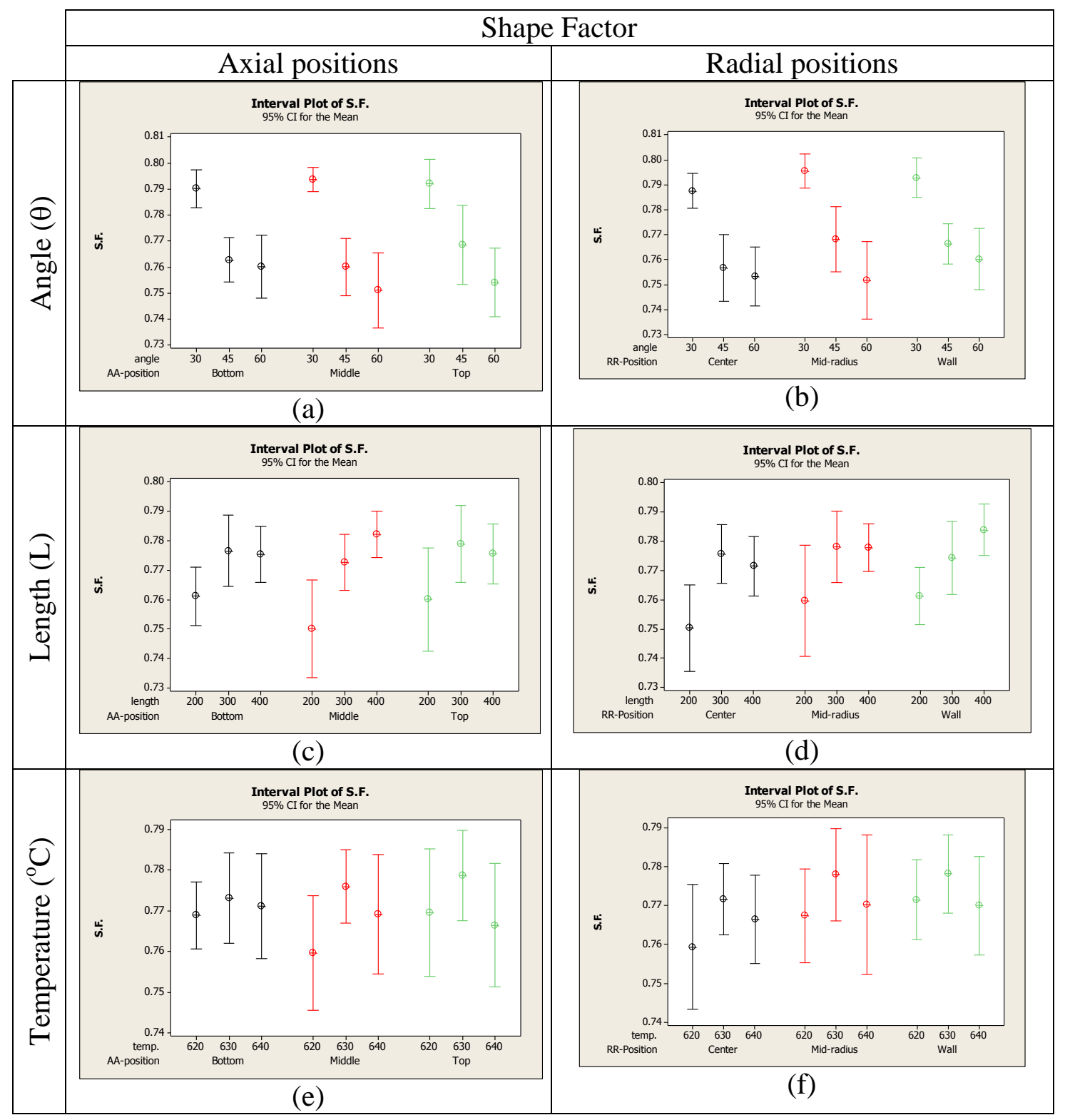

Fig. 9. Variation of shape factor of primary $\alpha-\mathrm{Al}$ grains with different values of tilt angle $\left(30,45\right.$ and $\left.60^{\circ}\right)$, cooling slope length $(200,300$ and $400 \mathrm{~mm})$ and pouring temperature $(620$, 630 and $\left.640{ }^{\circ} \mathrm{C}\right)$ at both $(\mathrm{a}, \mathrm{c}, \mathrm{e})$ axial and $(\mathrm{b}, \mathrm{d}, \mathrm{f})$ radial positions.

Table 4. ANOVA table for the shape factor of the $\alpha$-Al primary grains.

\begin{tabular}{|c|c|c|c|c|c|c|}
\hline $\begin{array}{l}\text { Source of } \\
\text { variation }\end{array}$ & DF & SS & MS & $\mathrm{F}$ & $\mathrm{P}$ & $\mathrm{P}_{\mathrm{c}}$ \\
\hline$\theta$ & 2 & 0.0601661 & 0.0300830 & 58.64 & 0.000 & 43.885 \\
\hline $\mathrm{L}$ & 2 & 0.0213010 & 0.0106505 & 20.76 & 0.000 & 15.537 \\
\hline $\mathrm{T}$ & 2 & 0.0041730 & 0.0020865 & 4.07 & 0.018 & 3.044 \\
\hline$\theta \times \mathrm{L}$ & 4 & 0.0074845 & 0.0018711 & 3.65 & 0.007 & 5.459 \\
\hline$\theta \times \mathrm{T}$ & 4 & 0.0161958 & 0.0040489 & 7.89 & 0.000 & 11.813 \\
\hline $\mathrm{L} \times \mathrm{T}$ & 4 & 0.0105761 & 0.0026440 & 5.15 & 0.001 & 7.714 \\
\hline$\theta \times \mathrm{L} \times \mathrm{T}$ & 8 & 0.0172036 & 0.0021504 & 4.19 & 0.000 & 12.548 \\
\hline Residual & 216 & 0.1108052 & 0.0005130 & & & \\
\hline Total & 242 & 0.1371001 & & & & 100 \\
\hline
\end{tabular}

DF, degrees of freedom; SS, sum of squares; MS, mean square; F,F-test; P, Statistical significance, $\mathrm{P}_{c}$, percentage of contribution. 


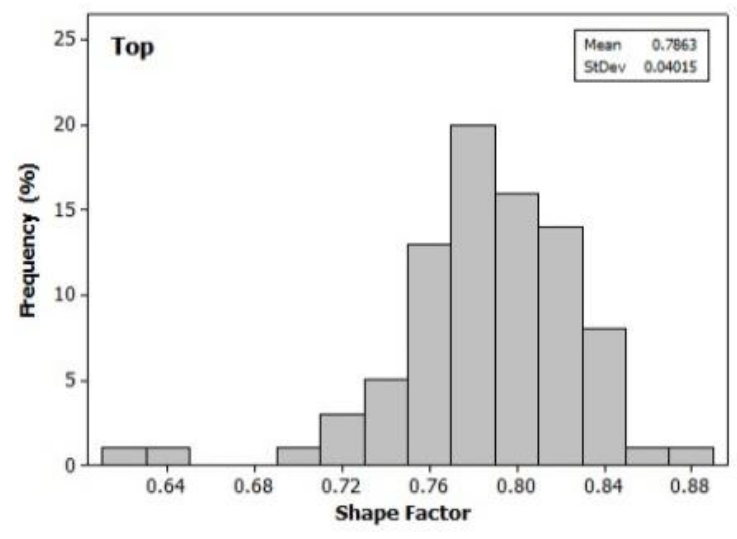

(a)

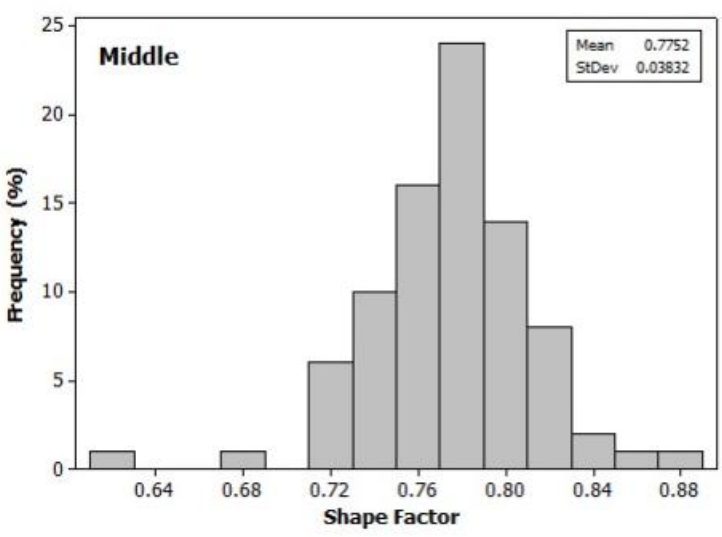

(b)

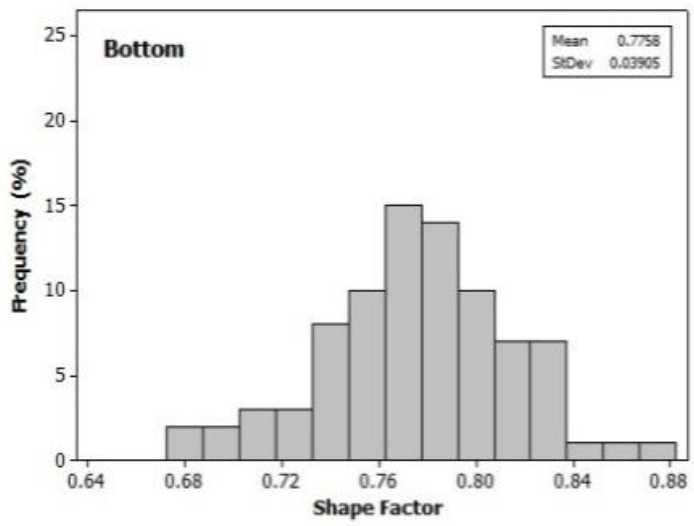

(c)

Fig. 10. Typical histograms of the shape factor of the $\alpha$ - $\mathrm{Al}$ primary grains at the top, center and bottom positions of A356 ingot poured at $30^{\circ}, 200 \mathrm{~mm}$ and $620^{\circ} \mathrm{C}$.

\section{CONCLUSIONS}

The conclusions of significance are drawn as follows:

1. The tilt angle exhibited the most statistical and physical significance effect on the grain size and shape factor of the $\alpha$-Al primary grains. Increasing the tilt angle from $30^{\circ}$ to $45^{\circ}$ reduced the average size of the primary $\alpha$-Al grains of the A356 aluminum alloy ingots. Increasing of the tilt angle to $60^{\circ}$ increases the average size of the primary $\alpha$ - $\mathrm{Al}$ grains.

2. The pouring temperature exhibited the least statistical and physical significance effect on the grain size and shape factor of the $\alpha-\mathrm{Al}$ primary grains. Increasing the pouring temperature from reduced the average grain size of the primary $\alpha$-Al grains

3. A356 aluminum alloy ingots poured at tilt angle, pouring temperature and cooling length of $60^{\circ}, 640{ }^{\circ} \mathrm{C}$ and $400 \mathrm{~mm}$, respectively, exhibited the maximum uniformity of grain size distribution at both the axial and radial directions. However, ingots poured at tilt angle, pouring temperature and cooling length of $30^{\circ}, 640{ }^{\circ} \mathrm{C}$ and $200 \mathrm{~mm}$, respectively exhibited the minimum uniform grain size distribution.

4. The maximum uniformity of the shape factor distribution was exhibited by ingots poured $30 \mathrm{o}, 300 \mathrm{~mm}$ and $640{ }^{\circ} \mathrm{C}$. While the minimum uniformity of the shape factor distribution was exhibited by ingots poured at $45^{\circ}, 200 \mathrm{~mm}$ and $620^{\circ} \mathrm{C}$.

\section{ACKNOWLEDGMENTS}

The authors are thankful to Benha University - Shoubra Faculty of Engineering for providing financial support and facilities for carrying out this work. 


\section{REFERENCES}

1. Hosseini SS, Nourouzi S, Hosseinipour SJ, Kolahdooz A (2012) "Effect of slope plate variable and pouring temperature on semi-solid microstructure of A356 aluminum alloy", in the $4^{\text {th }}$ international conference, Krakow, Poland,2012.

2. Farshid Taghavi, Ali Ghassemi (2009) Study on the effects of the length and angle of inclined plate on the thixotropic microstructure of A356 aluminum alloy, Materials and Design 30:1762-1767.

3. Budiman H, Omar MZ, Jalar A (2009) Effect of Water Cooling on the Production of AlSi Thixotropic Feedstock by Cooling Slope Casting, European Journal of Scientific Research 32:158-166.

4. Ghavamodini SM, Nourouzi S, Baseri H, Kolahdooz A," Effect of casting temperature and cooling system on the microstructure of Al-A356 feedstock produced by cooling slope method", in the 4th international conference on metal forming,Krakow,Poland,2012.

5. Cardoso Legoretta E, Atkinson HV, Jones H (2008) Cooling slope casting to obtain thixotropic feedstock II: observations with A356 alloy, Journal of Material Science 43:5456-5469.

6. Sadough SA, Rahmani MR, Pouyafar V (2010) Rheological behavior, microstructure and hardness of A356 aluminum alloy in semisolid state using backward extrusion process,

7. Transactions of Nonferrous Metals Society of China 20:906-910.

8. Prosenjit Das, Sudip .K. Samanta, Venkatpathi BRK., Himadri Chattopadhyay, Pradip Dutta (2012) Microstructural Evolution of A356 Al Alloy During Flow Along a Cooling Slope, Trans Indian Inst Met 65(6):669-672.

9. K. Sukumaran, Pai B C, Chakraborty M (2004) The effect of isothermal mechanical stirring on an $\mathrm{Al}-\mathrm{Si}$ alloy in the semisolid condition, journal of Materials Science and Engineering A, 369: 275-283.

10. Kaykham M, Kamarei A, Safari M, Arbabi V (2011) Semisolid structure and parameters for A360 aluminum alloy prepared by mechanical stirring, journal World Academy of Science Engineering and Technology, 73: 872-874.

11. Xiao-rong YANG, Wei-min MAO, Bin-yu SUN (2011) Preparation of semisolid A356 alloy slurry with larger capacity cast by serpentine channel, Transactions of Nonferrous Metals Society of China 21:455-460.

12. S. Deepak kumara, Pandu R. Vundavillia, Sisir Mantryb, A. Mandalc, M. Chakrabortyc, (2014) A Taguchi optimization of cooling slope casting process parameters for production of semi-solid A356 alloy and A356-5TiB2 in-situ composite feedstock, Procedia Materials Science 5:232 - 241.

13. Haga T, Nakamura R, Tago R, Watari H (2010) Effects of casting factors of cooling slope on semisolid condition, Transactions of Nonferrous Metals Society of China 20:968-972.

14. Hamed Khosravi, Reza Eslami-Farsani, Mohsen Askari-Paykani (2014) Modeling and optimization of cooling slope process parameters for semi-solid casting of A356 Al alloy, Transactions of Nonferrous Metals Society of China 24:961-968.

15. Pradip Dutta, Sricharan Babu K, Pratik H, Rahul K N, Maadhav P, Srinivasa Murthy P L (2014) Design and Fabrication of Cooling Slope for Semi-Solid Forming of Aluminium A356 Alloy, Journal of Mechanical Engineering Research and Technology 2:347-354.

16. Kund N K (2014) Influence of melt pouring temperature and plate inclination on solidification and microstructure of A356 aluminum alloy produced using oblique plate, Transactions of Nonferrous Metals Society of China 24:3465-3476. 